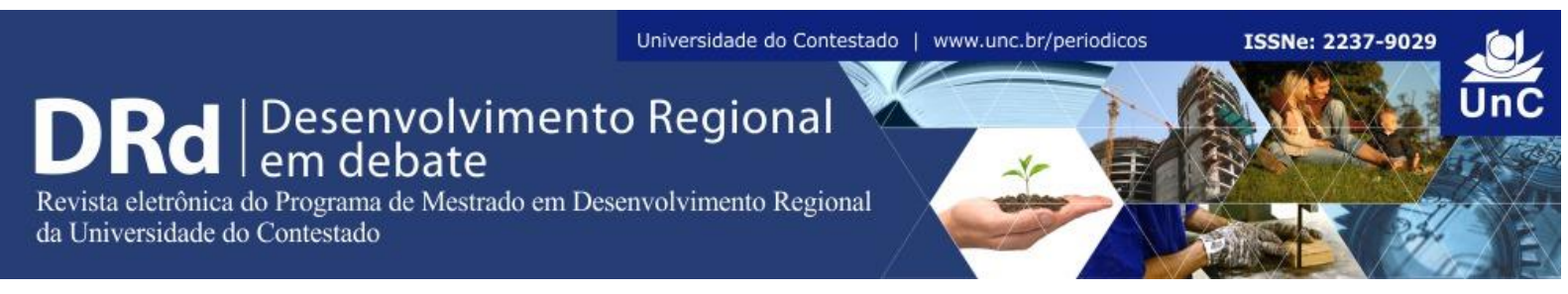

\title{
ECONOMIA SOLIDÁRIA: ALTERNATIVAS PARA O DESENVOLVIMENTO EM SÃO JOSÉ DO BARREIRO/SP ${ }^{1}$
}

\author{
Alan Alves Brito Conceição ${ }^{2}$ \\ Monica Franchi Carniello ${ }^{3}$ \\ Moacir José dos Santos ${ }^{4}$ \\ Edson Trajano Vieira ${ }^{5}$
}

\section{RESUMO}

A economia solidária é definida como modelo de produção e de distribuição alternativo às contradições da dinâmica da economia capitalista, especialmente à concentração de renda. Esse modelo econômico está estruturado em princípios democráticos. Por esse motivo, a gestão de uma empresa solidária deve contar com a participação de todos os envolvidos em seu funcionamento. O objetivo deste trabalho é analisar o potencial de constituição de empreendimentos de economia solidária em São José do Barreiro. A economia solidária adquiriu visibilidade no Brasil, a partir da década de 1980, devido ao aumento do desemprego e do subemprego. Este estudo, de caráter exploratório, foi desenvolvido por meio de pesquisa documental, com abordagem qualitativa. De acordo com o Índice FIRJAN, o problema de São José do Barreiro encontra-se na dificuldade para a geração de novos postos de trabalho. Uma opção para a superação deste ponto de estrangulamento está na formação de cooperativas de trabalho voltadas à produção de artesanato e à agricultura familiar. Outro ponto para ser explorado é o turismo rural e o de aventura. Desse modo, conclui-se que a economia solidária pode contribuir com melhoria do bem-estar no município.

Palavra-chave: Planejamento e Desenvolvimento Regional. Economia solidária. São José do Barreiro.

\footnotetext{
${ }^{1}$ Esse artigo faz parte dos resultados dos projetos: Desenvolvimento Econômico Local: ações de economia criativa em São José do Barreiro - SP e Assessoria Técnica para Desenvolvimento de Empreendimentos Econômicos Solidários na Microrregião de Bananal. Agradecemos à agência de fomento CNPq e ao PROEXT, pelo apoio financeiro aos projetos.

2 Mestre em Planejamento e Desenvolvimento Regional pela Universidade de Taubaté. Brasil. E-mail: alan.abc@ig.com.br

3 Doutora em Comunicação e Semiótica e professora do Programa de Mestrado em Planejamento e Desenvolvimento Regional da Universidade de Taubaté. Brasil E-mail: monicafcarniello@gmail.com

${ }^{4}$ Doutor em História e professor do Programa de Mestrado em Planejamento e Desenvolvimento Regional da Universidade de Taubaté. Brasil. E-mail: professormoacirsantos@ gmail.com

5 Doutor em História Econômica e professor do Programa de Mestrado em Planejamento e Desenvolvimento Regional da Universidade de Taubaté. Brasil. E-mail: edson.trajano@pq.cnpq.br
}

DRd - Desenvolvimento Regional em debate (ISSNe 2237-9029)

v. 5, n. 2, p. 188-206, jul./dez. 2015. 


\title{
SOLIDARY ECONOMY: AN ALTERNATIVE FOR DEVELOPMENT IN SÃO JOSÉ DO BARREIRO / SP
}

\begin{abstract}
The solidary economy is defined as a model of production and alternative distribution to clashes in the dynamics of the capitalist economy, especially the concentration of income. This alternative economic model is structured on democratic principles. For this reason, the management of a solidary enterprise should include the participation of all those involved in its operation. The objective of this study is to analyze the potential for the establishment of social economy enterprises to small municipalities, such as São José do Barreiro. The solidary economy has gained visibility in Brazil, from the 1980s, due to the growth of unemployment and underemployment. This study, exploratory, was conducted through documental research, with a qualitative approach. According to the FIRJAN Index, the difficult of São José do Barreiro is to generate new jobs. One option to overcome this bottleneck is the formation of labor unions, which could be aimed to the production of handicrafts and family farming. Another point can be explored is the rural and adventure tourism. Thus, it is concluded that the solidary economy can contribute to improving the well-being in the city.
\end{abstract}

Keywords: Planning and Regional Development. Solidary Economy. São José do Barreiro.

\section{INTRODUÇÃO}

Em 2013, de acordo com relatório do Instituto Brasileiro de Geografia e Estatística (IBGE) de 2014, o Produto Interno Bruto (PIB) do Brasil atingiu a cifra de 4,84 trilhões de dólares. Atualmente, o país está na sétima posição entre as principais economias do planeta. No entanto, o Brasil aparece apenas na $79^{\circ}$ posição no Índice de Desenvolvimento Humano (IDH) de 2013, portanto, não podendo ser considerado uma nação com alto desenvolvimento humano.

O contraste entre a riqueza presente no país e as informações contidas no IDH indica a necessidade de se organizar formas de desenvolvimento aptas a contribuírem para a redução das disparidades econômicas e sociais presentes no Brasil. Correlata a essa premissa, a economia solidária é uma alternativa para o desenvolvimento da sociedade. Apesar de estar inserida no sistema capitalista, tem como foco a valorização dos trabalhadores e não a do capital. O modelo solidário está estruturado no cooperativismo, na cogestão e, em alguns casos, na autogestão. "A economia solidária pode ser definida como o conjunto das atividades contribuindo para a democratização da economia a partir do engajamento dos cidadãos" (LAVILLE, 2001, p. 85).

Este trabalho parte do pressuposto de que a economia clássica não é capaz de atender aos anseios da sociedade contemporânea. Assim, a economia solidária apresenta-se como alternativa para a redução dos problemas resultantes da desigualdade social brasileira. Partese do pressuposto de que o capitalismo está propenso a agravar as crises econômicas por meio da concentração de renda e exclusão social. Em pequenos municípios, os problemas inerentes à dinâmica capitalista tendem a ampliar as consequências da desigualdade social e econômica 
em razão da estagnação da atividade produtiva e da dificuldade de se estabelecer conexões com os pólos de atividade produtiva mais intensa. As dificuldades dos pequenos municípios do Vale do Paraíba, situados entre pólos econômicos dinâmicos, como São Paulo, Rio de Janeiro, São José dos Campos e Taubaté fundamentaram a realização da pesquisa que sustenta este artigo, justificada pela falta de perspectiva profissional nos pequenos municípios. $\mathrm{O}$ objetivo deste trabalho é analisar o potencial de constituição de empreendimentos de economia solidária em São José do Barreiro.

\section{ECONOMIA SOLIDÁRIA COMO ESTRATÉGIA PARA O DESENVOLVIMENTO TERRITORIAL}

\subsection{ECONOMIA SOLIDÁRIA}

O conceito de economia solidária teve origem nas experiências dos socialistas utópicos, como Robert Owen, ainda na primeira metade do século XIX, na Inglaterra. Owen teve contribuição decisiva ao colocar em prática os ideais democráticos de igualdade e solidariedade, com o objetivo de melhorar a qualidade de vida dos trabalhadores (SINGER, 2003). A emergência da economia solidária esteve associada aos impactos negativos da primeira Revolução Industrial, que acarretou na exclusão dos artesãos do mercado de trabalho. Owen foi pioneiro na implantação da jornada de trabalho e na restrição ao trabalho infantil (RETAMIRO, 2013, p. 73). A implantação de cooperativas, com caráter socialista, ocorreu no momento em que a Revolução Industrial fortalecia o ideal da economia liberal de Adam Smith.

O liberalismo econômico foi desenvolvido a partir do século XVI para atender às necessidades do sistema capitalista. Este modelo tem como pressuposto a emancipação da economia, a não intervenção do Estado. O Estado deveria se concentrar em oferecer condições adequadas para que a economia seguisse seu rumo natural. $O$ conceito de mão invisível do mercado determina que os agentes econômicos devem atuar livremente para alcançar a eficiência máxima, sem a intervenção de um órgão regulador. O interesse da coletividade seria alcançado a partir de ações individuais. Como cada indivíduo tende a atuar de maneira a satisfazer suas próprias necessidades, indiretamente, essas ações isoladas convergiriam para atender ao interesse comum, como se houvesse uma mão invisível que regula automaticamente o mercado (SMITH, 1985).

O inglês David Ricardo é um dos fundadores da escola clássica de economia. Ricardo aborda questões relacionadas ao modo de distribuição do produto gerado pelo trabalho da sociedade. Ele "[...] defende a concentração de renda em favor dos capitalistas urbanos industriais, por serem responsáveis pela acumulação que determina o crescimento econômico, gerando mais emprego e desenvolvimento" (VIEIRA, 2009, p. 28). Para Ricardo, qualquer restrição ao comércio seria prejudicial ao crescimento da economia. "De modo geral, defende a idéia de que existe uma harmonia social engendrada pela 'mão invisível' do mercado livre" (HUNT, 1981, p. 139). Essa argumentação está baseada na teoria das vantagens comparativas. Este princípio defende a tese de que um país não precisa ter uma vantagem absoluta na produção de qualquer mercadoria para que o comércio entre países ou regiões seja 
mutuamente benéfico. Os ideais de Ricardo estão centrados no crescimento da economia que, consequentemente, levariam ao bem-estar da sociedade.

Em oposição à teoria das vantagens comparativas de Ricardo, a teoria marxista estabelece a crítica à primeira Revolução Industrial, ocorrida na Inglaterra entre 1760 e 1840. A transição no processo de produção artesanal para o modelo industrial fez com que a Inglaterra produzisse cada vez mais, enquanto sua população estava cada vez mais pobre. A partir das primeiras décadas do século XIX, houve um crescimento relativo da renda dos trabalhadores, o que não eliminou a pobreza e a exploração dos trabalhadores (BERTUCCI, 2010). No sistema capitalista, de acordo com a teoria marxista, o proletariado é visto apenas como um meio para que o burguês alcance a maximização do lucro. Dessa forma, o trabalhador é tratado como um número que pode ser substituído ou descartado a qualquer momento como uma ferramenta ultrapassada. A teoria marxista critica o sistema econômico capitalista burguês, pois:

[...] cada empresa ou sociedade pensa em monopolizar todas as vendas para si, e para este efeito produz tanto quanto pode, vendo-se obrigada a produzir sem cessar pelo interesse que tem em não deixar descansar um momento os custosos instrumentos de produção. Deste modo o mercado enche-se; as mercadorias amontoam-se, abundantes e invendáveis; estalam crises, que renovam periodicamente, e então os operários deixam de trabalhar e morrem de fome porque foram obrigados a produzir demasiados artigos de consumo (MARX, 1998, p. 25).

A exploração da mão de obra não foi uma novidade. Porém, o sistema capitalista foi responsável pelo que Marx denominou como mais valia relativa. A mais valia relativa “[...] pressupõe a apropriação de inovações incorporadas em máquinas e equipamentos mais eficientes e modernos, em insumos mais adequados e na melhoria da organização social do trabalho, que elevam a produtividade" (GALVÃO, 2004, p. 49). Dessa forma, a acumulação da riqueza é constantemente apropriada pelo capitalista, o que vai determinar a concentração da renda.

O crescimento da indústria burguesa produziu o proletariado e, logo em seguida, a ampliação dessa classe. No entanto, à medida que as máquinas eram aperfeiçoadas, os salários dos trabalhadores eram cada vez mais comprimidos.

"No capitalismo, o crescimento econômico é, como Marx o nomeia usualmente, um processo de contradições internas, que, frequentemente, irrompe sob a forma de crises" (HARVEY, 2005, p. 44). Essas contradições negativas do capitalismo são apresentadas na forma de desemprego e subemprego. O capital cresce com a exploração do trabalho e o bloqueio a sua expansão implica prejuízos para os trabalhadores. Para Harvey, o cresciemnto econômico capitalista depende da exploração do trabalho e das condições de sua execução. $\mathrm{O}$ sistema capitalista é movido pela acumulação de capital e, para que isso ocorra, há necessidade de um excedente de mão de obra, a esse excedente, Marx denominou "exército de reserva. "Para os capitalistas, os salários pagos aos trabalhadores nada mais eram do que outras despesas no processo de produção que, contabilizados, determinavam o lucro do capitalista. O trabalhador vendia a sua mercadoria conforme o interesse do comprador" (SANTOS; VIEIRA, 2012, p. 352).

As contradições do capitalismo, apontadas por Marx, foram retomadas sob outra perspectiva por John Maynard Keynes, que defendia o princípio de que o Estado deve intervir na economia do país por meio de medidas fiscais e monetárias para minimizar os efeitos

DRd - Desenvolvimento Regional em debate (ISSNe 2237-9029) 
negativos dos ciclos econômicos. As ideias de Keynes, no início do século XX, deram origem à teoria macroeconômica, implantada por diversos países capitalistas para solucionar os problemas causados com a crise de 1929 e a Grande Depressão, na década de 1930. O keynesianismo "[...] é uma doutrina ativista, que preconiza a ação do Estado na promoção e sustentação do pleno emprego em economias empresariais" (CARVALHO, 2008, p. 571).

Atualmente, a escola keynesiana voltou ao debate político, econômico e acadêmico devido à crise econômica mundial, ocasionada pelo sistema financeiro capitalista. Em pauta, o intervencionismo estatal. Nas décadas de 1970 e 1980, pensadores neoliberais consideravam as teorias de Keynes ultrapassadas.

O pensamento neoliberal é criticado por diversos setores da sociedade. O principal questionamento está no fato de que o neoliberalismo beneficiaria apenas as principais potências econômicas. Portanto, os países pobres e aqueles em estágio de desenvolvimento seriam prejudicados, agravando o desemprego, reduzindo o poder de compra, crescimento da dependência com relação ao capital externo e aumento das disparidades sociais. Consequentemente estaria sendo perpetuado o ciclo vicioso da pobreza extrema, com a ampliação da polarização entre miseráveis e milionários.

No Brasil, a economia solidária surge no meio urbano a partir da década de 1980, devido ao crescimento do desemprego e, como consequência das altas taxas de inflação. Antes desse período, há apenas relatos de cooperativismo no meio rural. Somente a partir dos anos de 1990, o modelo solidário se fortaleceu:

[...] resulta de movimentos sociais que reagem à crise de desemprego em massa, que tem seu início em 1981 e se agrava com a abertura do mercado interno às importações, a partir de 1990. Em 1991, tem início o apoio de assessores sindicais a operários que conseguem se apossar da massa falida da empresa que antes os empregava, formando uma cooperativa de produção, que retoma as operações e assim 'salva' os postos de trabalho até então ameaçados de fechamento. Três anos depois, diversas empresas autogestionárias com esta origem fundam a Associação Nacional de Trabalhadores em Empresas Autogestionárias e de Participação Acionária (Anteag) (SINGER, 2003, p. 25).

Conforme definição da Secretaria de Economia Solidária (SENAES) a Economia Solidária é um jeito diferente de produzir, vender, comprar e trocar o que é preciso para viver. Sem exploração do trabalho em favor do capital, com a correspondente preservação do ambiente. Cooperando, fortalecendo o grupo, mediante a perspectiva das conquistas coletivas. A Economia Solidária é caracterizada por atividades econômicas de produção, distribuição, consumo, poupança e crédito, sob a forma de autogestão, metodologia abordada mais adiante. Desta forma, ainda sob a ótica da SENAES, é possível caracterizá-la pelos seguintes pontos:

-Cooperação: união dos esforços e capacidade desenvolvendo diversos tipos de organização coletiva;

-Autogestão: adotam-se as práticas participativas de gestão nas definições estratégicas e cotidianas dos empreendimentos, etc.;

-Dimensão Econômica: envolve o conjunto de elementos de viabilidade econômica, permeados por critérios de eficácia e efetividade, ao lado dos aspectos culturais, ambientais e sociais; 
-Solidariedade: justa distribuição dos resultados alcançados. (SENAES, 2015).

O conceito de economia solidária é definido “[...] por práticas econômicas de iniciativa de pessoas livremente associadas, com algumas características básicas: algum grau de socialização dos meios de produção; dispositivos de cooperação no trabalho; elementos de gestão democrática" (GAIGER, 2009, p. 570). Verifica-se que a economia solidária está estruturada na organização coletiva de trabalho.

A economia solidária:

[...] tem como especificidade combinar dinâmicas de iniciativas privadas com propósitos centrados não no lucro, mas no interesse coletivo. A razão econômica é acompanhada por uma finalidade social que consiste em produzir vínculos sociais e solidários, baseados numa solidariedade de proximidade; o auxílio mútuo e a reciprocidade estariam, assim, no âmago da ação econômica [...] A segunda característica da economia solidária reside na elaboração de formas de coordenação e de alocação de recursos alternativas à concorrência ou à regulamentação administrativa representada pela coordenação estatal (LEITE, 2008, p. 34).

A constituição da economia solidária situa-se, historicamente, a partir da crise de produção do capitalismo e devido à ascensão do neoliberalismo, que acarretou em prejuízos às camadas menos favorecidas da sociedade. Neste contexto, a população pobre tem como opção a auto-organização para desenvolver atividades “[...] econômicas para geração alternativa de trabalho e renda, tais como: cooperativas, empresas autogestionárias, sistemas de trocas não-monetárias, bancos populares, entre outras" (AZAMBUJA, 2009, p. 286).

O engendrar da economia solidária implica na emancipação dos trabalhadores, especialmente com a transformação das relações de gênero sob o imperativo da igualdade. Com relação à mulher, a economia solidária "[...] significou a possibilidade de alargar seus horizontes em relação à participação social e política, como o fato de poderem ir a uma reunião de bairro, ou a uma reunião do próprio empreendimento, participar de cursos e visitas técnicas" (LANZA; STÁBILE, 2012, p. 146). A economia solidária reconhece a capacidade que toda pessoa tem para desempenhar determinada função, independentemente do gênero, e também pode ser vista como:

[...] uma alternativa a essa sociedade dominada pelos princípios do mercado. A consciência por parte dos indivíduos das armadilhas criadas pela economia capitalista poderia culminar no surgimento de empreendimentos solidários originais, ou seja, aqueles que funcionam de acordo com a proposta da Economia Solidária. Tal proposta passa certamente pela idéia de que a existência humana não se resume à atuação enquanto agente organizacional, mas compreende aspectos muito mais profundos e substantivos dos indivíduos (BARRETOS; PAULA, 2009, p. 203).

A efetivação dos empreendimentos da economia solidária implica o questionamento do modelo de consumo desordenado da sociedade contemporânea. A luta por concretizar as ações relacionadas à economia solidária correlaciona-se a percepção de que as raízes deste processo estão situadas em movimentos sociais, com o objetivo de inclusão social. Ao contrário do modelo atual, que exclui parte significativa da sociedade devido à falta de poder de compra. Dessa maneira, compreende-se economia solidária como um modelo econômico alternativo. O que pressupõe um consumo consciente, ou seja, respeito ao meio ambiente. "A perspectiva democrática dos empreendimentos de economia solidária é um pressuposto teórico apontado por vários autores que fundamentam a proposta de criar organismos 
econômicos alternativos" mesmo estando inseridos numa economia de mercado (GUGLIANO; LOCKS, 2013, p. 42).

\subsection{CRESCIMENTO ECONÔMICO E O DESENVOLVIMENTO}

O IDH é utilizado anualmente pelo Programa das Nações Unidas para o Desenvolvimento (PNUD), desde sua criação, em 1993, para avaliar a qualidade de vida nos países. A criação desse índice rendeu o Nobel de Economia, em 1998, para um de seus criadores, o economista indiano Amartya Sen. O objetivo do PNUD é ampliar as possibilidades de escolha do indivíduo para que ele possa ser aquilo que deseja ser. $\mathrm{O}$ desenvolvimento humano pressupõe que, para a obtenção da qualidade de vida de uma sociedade, é necessário romper as barreiras econômicas para conquistar a melhoria na qualidade de vida, atendendo a questões relacionadas à segurança, liberdade, justiça social, proteção ao meio ambiente, além de fatores culturais.

Por esse motivo, é importante compreender as diferenças conceituais entre crescimento e desenvolvimento. Crescimento econômico é o resultado do crescimento da capacidade produtiva de bens e serviços de certo país ou região econômica (SANDRONI, 1994). Esse aumento é mensurado a partir da variação anual do PIB.

O PIB consiste na soma de todos os bens e serviços finais de determinada região, durante certo período. É considerado uma das principais ferramentas para mensurar a atividade econômica de uma nação, estado ou município. Contudo, o PIB apresenta limites por não considerar fatores relacionados à saúde, à educação e à qualidade de vida. O PIB não é uma medida perfeita para avaliar o bem-estar, mas pode ser considerado como um dos principais indicadores, desde que se considere suas limitações (MANKIW, 2005).

Outra forma de avaliar o crescimento econômico é por meio do crescimento da força de trabalho e o nível tecnológico adquirido. Já o conceito de desenvolvimento econômico é uma questão mais ampla, abrange tanto o crescimento econômico quanto a melhoria na qualidade de vida da população (VIEIRA, 2009). Essa análise é feita com base em indicadores sociais que avaliam a distribuição de renda, escolaridade, emprego, saúde e renda. Dessa forma,

[...] o conceito de desenvolvimento depende dos valores historicamente construídos de cada sociedade embora conserve em seu cerne a conquista de padrões de vida mais elevados acessíveis à maioria da população. Sob esse prisma o conceito de desenvolvimento pode até ser oposto à ideia de progresso econômico, pois seu objetivo é mais do que a oferta de bens e serviços resultantes do aumento de produtividade (SANTOS, VIEIRA, 2012, p. 348).

O desenvolvimento, devido ao grande número de variáveis, torna-se um fenômeno complexo para ser mensurado com exatidão. Contudo, deve ser considerado que desenvolvimento pressupõe o bem-estar humano. "O desenvolvimento não decorre apenas do crescimento e do acúmulo de riquezas, como defendem os economistas mais conservadores, é possível que, com a distribuição da mesma, também teremos condições para promover o desenvolvimento" (BRAGA et al. 2012, p. 59). 
Desse modo, verifica-se a pertinência da utilização do PIB. Contudo, esta é uma ferramenta que não pode ser manuseada isoladamente, é necessário utiliza-la com outros indicadores como IDH, o coeficiente de Gini ${ }^{6}$ e o índice FIRJAN.

O uso conjunto dos indicadores implica na produção de referencias para a adequada avaliação da realidade econômica e social de cada região ou localidade. Denota-se a possibilidade de estruturar ações de transformação de condições sociais precárias a partir do adequado conhecimento das deficiências do processo de desenvolvimento. Os indicadores constituem as principais referencias para o processo de planejamento relativo ao desenvolvimento regional, pois produzem os subsídios necessários as parcerias entre os setores público e privado para que os pequenos municípios tenham acesso ao crédito. A atividade deve ter como foco o desenvolvimento e a implementação de estratégias para o fortalecimento da produção, com o envolvimento de agentes econômicos, políticos e sociais. A união desses atores tende a fortalecer o elo para a superação dos gargalos que afetam a produtividade das comunidades. O desenvolvimento regional sustentável "[...] propõe à comunidade e aos parceiros centrais o foco de atuação no desenvolvimento, dando condições de organização e articulação entre os parceiros para estabelecer boas relações e um projeto comum" (FRANCO, 2006, p. 78).

A partir desse estreito relacionamento entre a comunidade, setor público e instituições privadas, formula-se a possibilidade de implantação de projetos econômicos solidários. $\mathrm{O}$ desafio "[...] é traduzir o esforço dos parceiros numa capacidade de articulação dos atores sociais, porque a mobilização é que garante a sustentabilidade dos projetos. As idéias podem ser ótimas, mas, se não estiverem enraizadas na população, não haverá sequência" (FRANCO, 2006, p. 81). Uma maneira de colocar em prática esses ideais é incentivar os produtores locais a participarem de exposições para expandir a comercialização de seus produtos.

"O que tem ocorrido nas últimas décadas foi o aumento da exploração das regiões mais pobres pelas mais ricas, por ineficiência das políticas públicas, com uma ação cada vez mais limitada do Estado" (SANTOS; VIEIRA, 2012, p. 367). Desse modo, entende-se que é necessário romper as barreiras econômicas para alcançar o desenvolvimento. Para que essa ideia possa ser concretizada, é necessário propor maneiras alternativas de gestão solidária.

\section{MÉTODO}

Este artigo foi elaborado com base na pesquisa qualitativa, pois este meio oferece maior abrangência para a investigação de fenômenos inseridos nas ciências humanas. A abordagem qualitativa apresenta uma estrutura mais flexível aos pesquisadores, explorando novos enfoques (GODOY, 1995). Nesse segmento, encontra-se a pesquisa do tipo documental. A vantagem desse tipo de pesquisa está na possibilidade de estudar, por meio de documentos, os fatos históricos.

\footnotetext{
${ }^{6}$ Instrumento desenvolvido pelo italiano Conrado Gini, em 1912, para calcular a desigualdade na distribuição de renda. A avaliação varia de 0 a 1, quanto mais próximo de zero, menor a desigualdade. Consequentemente, 0 número um representa o máximo de desigualdade.
}

DRd - Desenvolvimento Regional em debate (ISSNe 2237-9029) 
Os documentos devem ser considerados como "[...] uma fonte natural de informação à medida que, por terem origem num determinado contexto histórico, econômico e social, retratam e fornecem dados sobre esse mesmo contexto" (GODOY, 1995, p. 22). Destarte, justifica-se a contextualização sobre a origem da economia solidária no início do século XIX e seu surgimento no cenário brasileiro.

Outra ferramenta utilizada para o desenvolvimento deste trabalho foi o método da observação assistemática, com o intuito de compreender a movimentação espontânea dos agentes sociais envolvidos na pesquisa. $O$ registro de tal fato oferece credibilidade ao formular hipóteses concretas relacionadas à investigação do problema. "A observação consiste apenas em ajustar a realidade ao que já se sabe. $\mathrm{O}$ ajuste vai depender da qualidade das informações que se possui previamente. É, portanto, a pré-concepção que condiciona o resultado" (FREITAS; MOSCAROLA, 2002, p. 11). Neste caso, a observação realizada com o mínimo possível de interferência tende a refletir com transparência a opinião dos envolvidos sobre determinado assunto.

A situação do desenvolvimento no município de São José do Barreiro foi analisada por meio do Banco de Dados do Instituto de Pesquisa Econômica Aplicada (Ipeadata) e a partir de resultados do Censo Demográfico dos anos 2000 e 2010, realizado pelo IBGE. Os estudos a respeito da qualidade de vida do município foram realizados com base em informações do Índice FIRJAN de Desenvolvimento Municipal, além de dados da Fundação Sistema Estadual de Análise de Dados (Seade).

\section{RESULTADOS E DISCUSSÃO}

\subsection{INDICADORES DE DESENVOLVIMENTO DO MUNICÍPIO DE SÃO JOSE DO BARREIRO}

O município de São José do Barreiro está localizado na Região Metropolitana do Vale do Paraíba e Litoral Norte ${ }^{7}$ (RMVale), mais precisamente, na microrregião de Bananal $^{8}$, considerada a mais pobre dessa mesorregião. No entanto, São José do Barreiro foi considerado um dos municípios mais ricos do estado de São Paulo em meados do século XIX. Entre os anos de 1853 e 1854, a produção de café do estado do Rio de Janeiro atingiu aproximadamente oito milhões de arrobas, enquanto, a região do Vale do Paraíba paulista somava quase três milhões de arrobas (MOTTA SOBRINHO, 1978).

Os municípios pertencentes à microrregião de Bananal prosperaram economicamente no período auge do café. O Vale do Paraíba paulista, durante o século XIX, foi caracterizado pela monocultura cafeeira e mão de obra escrava. A produção do ouro negro no Vale estava associada à capital federal da época, o Rio de Janeiro (RICCI, 2006, p. 39). Mesmo em

\footnotetext{
7 Uma das 15 mesorregiões pertencentes ao estado de São Paulo. De acordo com o IBGE, essa região metropolitana abrange uma área de $16.268 \mathrm{~km}^{2}$, constituída de outras seis microrregiões, totalizando 39 municípios. A RMVale foi constituída em 9 de janeiro de 2012. Em período anterior a essa data, a região era denominada como Vale do Paraíba paulista.

${ }^{8}$ A microrregião de Bananal é constituída pelos municípios de Arapeí, Areias, Bananal, São José do Barreiro e Silveiras.
} 
condições desfavoráveis, a região manteve a monocultura da commodity. Fato este que dificultou o processo de diversificação e de modernização da agricultura e, consequentemente, inviabilizou o surgimento de novas oportunidades.

"Em 1883, a produção cafeeira paulista igualou-se à fluminense, ultrapassando-a, nos anos seguintes, e distanciando-se cada vez mais" (MOTTA SOBRINHO, 1978, p. 30). O transporte ferroviário trouxe benefícios aos fazendeiros de outras regiões, pois reduziu a perda de mercadoria e diminuiu o custo referente aos encargos da tropa. Para Bananal foi prejudicial, pois a microrregião foi deslocada da rota Rio-São Paulo. A implantação da ferrovia favoreceu a interiorização do café. "Os custos de transporte por tropas de muares eram de tal ordem (chegavam a 50\% do valor da saca de café) que impossibilitavam a expansão para o interior" (CANO 1990, p. 17-23 apud RICCI, 2006, p. 43). A partir deste ponto, o café começa a mudar sua rota com destino ao oeste do estado de São Paulo.

A monocultura do café transformou as produtivas terras do Norte de São Paulo em terras improdutivas. Além disso, a proximidade desses municípios ao estado do Rio de Janeiro fez com que estivessem mais vulneráveis às fragilidades econômicas da família real do que com o dinamismo da capital paulista. Outro fator fundamental para a consolidação da decadência de São Jose do Barreiro e cidades adjacentes foi a construção da Rodovia Presidente Dutra, em 1951.

Atualmente, São José do Barreiro possui 4.190 habitantes, segundo dados de 2013 do IBGE. Em 1999, o município registrou PIB de R \$10,54 milhões; em 2011, esse valor saltou para $\mathrm{R} \$ 48,39$ milhões; nesse período, o PIB municipal teve crescimento de 359\%. Apesar de o resultado ser expressivo, quando comparado ao PIB regional, esse número torna-se insignificante. Em 1999, o PIB de São José do Barreiro representava 0,048\% do PIB do Vale do Paraíba. Em 2011, esse percentual subiu para 0,077\%. A Tabela 1 apresenta uma comparação entre os PIBs, municipal, regional e estadual, em números absolutos.

Tabela ${ }^{9} 1$ - Evolução do PIBno estado de São Paulo, no Vale do Paraíba e em São José do Barreiro entre os anos de 1999 e 2011 (milhões de reais correntes)

\begin{tabular}{lccccc}
\hline & $\mathbf{1 9 9 9}$ & $\mathbf{2 0 0 3}$ & $\mathbf{2 0 0 7}$ & $\mathbf{2 0 1 1}$ & $\begin{array}{c}\text { Variação } \\
\mathbf{1 9 9 9 / 2 0 1 1}\end{array}$ \\
\cline { 2 - 5 } Estado de São Paulo & $383.249,57$ & $579.846,92$ & $902.784,27$ & $1.349 .465,14$ & $252 \%$ \\
Vale do Paraíba & $21.759,52$ & $32.482,10$ & $45.876,24$ & $63.150,52$ & $190 \%$ \\
São José do Barreiro & 10,54 & 17,11 & 27,21 & 48,39 & $359 \%$ \\
\hline
\end{tabular}

Fonte: IBGE/Seade (2014).

Com relação ao PIB per capita, é possível observar, por meio do gráfico 1, que quando comparado Estado, região e município, percebe-se que São José do Barreiro possui o menor valor. Em 1999, seu PIB per capita era de $\mathrm{R} \$ 2.560,90$ e em 2011, o rendimento passou para $\mathrm{R} \$ 11.871,08$. No período de 12 anos, a cidade apresentou crescimento de 363,70\%, percentual superior àquele que foi alcançado, tanto pelo Estado (207,80\%), quanto pela região $(147,54 \%)$. Esse crescimento na renda per capita do município é justificado pela ampliação do número de beneficiários e o aumento do recurso destinado aos programas sociais do Governo Federal, entre 2003 e 2010. Além de políticas macroeconômicas voltadas para o

${ }^{9}$ Os anos selecionados na Tabela 1 foram definidos por meio de viés político; 1999, segundo governo Fernando
Henrique Cardoso; 2003, primeiro governo Lula; 2007, segundo governo Lula; 2011, governo Dilma Rousseff. Henrique Cardoso; 2003, primeiro governo Lula; 2007, segundo governo Lula; 2011, governo Dilma Rousseff.

DRd - Desenvolvimento Regional em debate (ISSNe 2237-9029) 
crescimento real do salário mínimo e o controle da inflação, que impactaram no aumento do poder de compra do brasileiro.

Gráfico 1 - Comparação entre o crescimento do PIB per capita de São José do Barreiro, Vale do Paraíba e o estado de São Paulo entre 1999 e 2011 (em mil reais correntes)

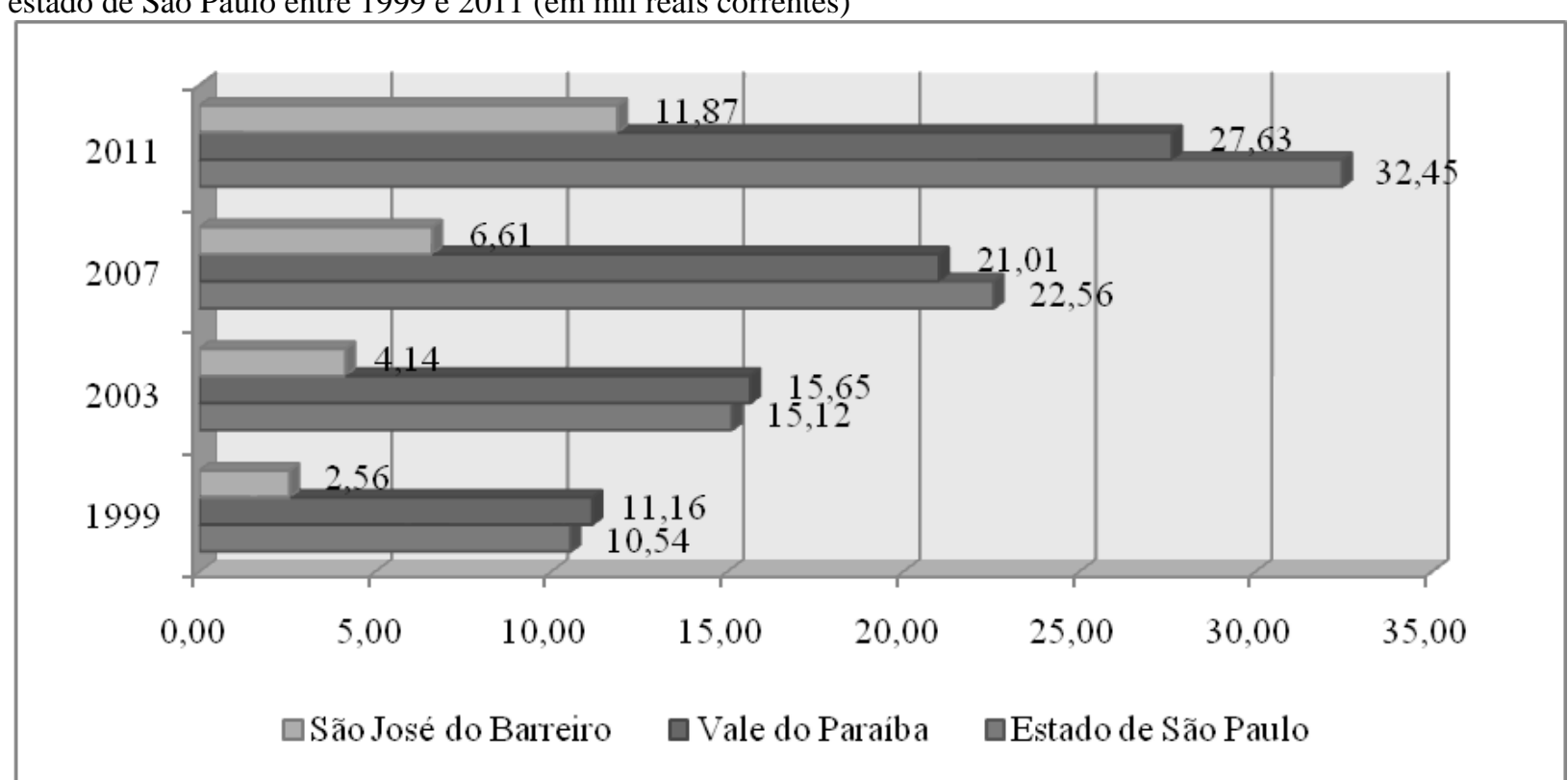

Fonte: IBGE/Seade (2014).

De acordo com a Tabela 2, o estado de São Paulo, entre 1980 e 2012, teve crescimento populacional de 68\%. A mesma tendência foi verificada no Vale do Paraíba, que obteve aumento de $90 \%$ na população. No entanto, o município de São José do Barreiro, ao longo dessas três décadas, manteve praticamente estável seu número de habitantes, com variação positiva de $0,8 \%$. Fato este que explica a estagnação econômica da cidade.

Tabela 2 - Crescimento populacional no estado de São Paulo entre 1980 a 2012

\begin{tabular}{l|ccccc}
\hline & $\mathbf{1 9 8 0}$ & $\mathbf{1 9 9 0}$ & $\mathbf{2 0 0 0}$ & $\mathbf{2 0 1 0}$ & $\mathbf{2 0 1 2}$ \\
\hline Estado de São Paulo & 24.953 .238 & 30.783 .108 & 36.974 .378 & 41.223 .683 & 41.939 .997 \\
Vale do Paraíba & 1.215 .549 & 1.598 .614 & 1.988 .498 & 2.262 .135 & 2.309 .772 \\
São José do Barreiro & 4.040 & 3.946 & 4.141 & 4.078 & 4.074 \\
\hline
\end{tabular}

Fonte: IBGE/Seade (2014).

A análise da variação demográfica é uma ferramenta importante para a pesquisa, pois permite verificar qual a situação econômica do município. No caso de crescimento econômico, observa-se que há um aumento no número de habitantes, pessoas que migram de uma localidade para outra em busca de oportunidades de emprego. Já no caso de estagnação econômica, a população tende a evadir-se da cidade devido à falta de perspectiva. Consequentemente, os jovens talentos acabam sendo transferidos para os centros urbanos, retornando à sua cidade natal somente após conquistarem a aposentadoria. Assim, perpetuam a defasagem na mão de obra qualificada e a falta de serviços especializados.

Outro indicador adequado à mensuração dos efeitos das políticas públicas e da desigualdade social brasileira é o índice FIRJAN de Desenvolvimento Municipal, elaborado

DRd - Desenvolvimento Regional em debate (ISSNe 2237-9029) 
pela Federação das Indústrias do Rio de Janeiro com o objetivo de avaliar o desempenho dos municípios brasileiros. Esse indicador abrange as áreas de emprego e renda, educação e saúde, a partir de informações oficiais disponibilizadas pelos Ministérios do Trabalho, da Educação e da Saúde. O índice varia de 0 a 1 . Quanto mais próximo de 1, maior o grau de desenvolvimento do município. A segmentação da pesquisa permite verificar qual a área com maior e menor desempenho. Dessa forma, facilita o desenvolvimento de projetos para superar os gargalos de desenvolvimento detectados.

Em 2011, São José do Barreiro ficou na $2.312^{\circ}$ posição no ranking nacional do IFDM, consolidado dentre os 5.565 municípios brasileiros. Na classificação estadual, o município aprece na posição de número 584, dentre as 645 cidades do estado de São Paulo.

Na última década, o IFDM de São José do Barreiro teve alta oscilação no grau de desenvolvimento moderado (entre 0,6 e 0,8). Como observado no gráfico 2, com forte tendência para cair ao nível de desenvolvimento regular (entre 0,4 e 0,6 ). A maior pontuação alcançada pelo município foi em 2011, quando chegou a 0,6601. No período de 2005 até 2011, foi registrado crescimento de 4,38\%. No entanto, verifica-se que, do ano de 2006 para 2007, o município apresentou queda de 9,33\% no IFDM. Esse último ano, foi quando São José do Barreiro apresentou seu pior resultado $(0,5804)$ na série histórica apresentada pelo IFDM.

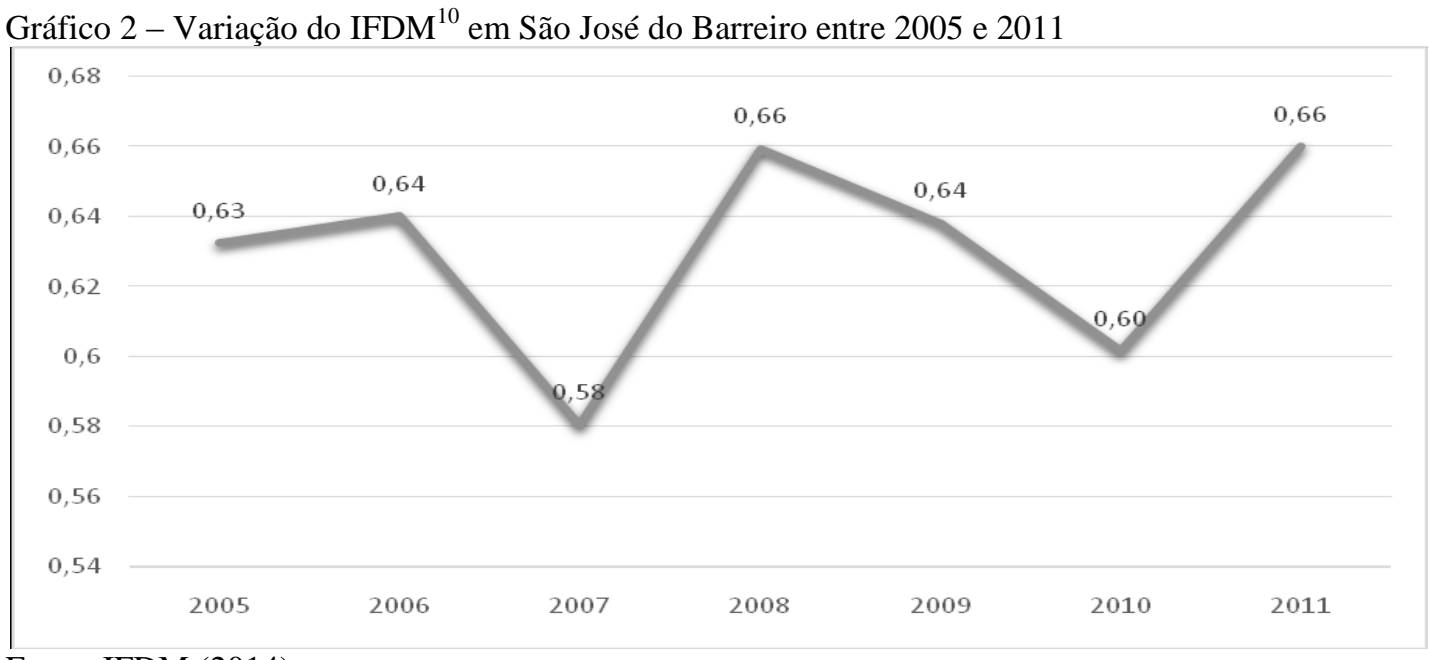

Fonte: IFDM (2014).

Em 2008, São José do Barreiro apresentou crescimento de 13,63\% em relação ao ano anterior. Nos anos seguintes, 2009 e 2010, o índice retomou a trajetória de queda com notas 0,6382 e 0,6015; respectivamente (o resultado de 2010, quando comparado com o de 2008, representou um retrocesso de $8,79 \%$ ). Para que a cidade obtenha alto grau de desenvolvimento, é necessário que a nota seja maior do que 0,8 . Nos critérios de avaliação, o município com nota inferior a 0,4 será considerado com baixo nível de desenvolvimento.

O gráfico 3 traz em detalhe as notas obtidas por São José do Barreiro referentes ao IFDM, entre 2005 e 2011. Quando o Índice FIRJAN é analisado individualmente, observa-se que o ponto de estrangulamento de São José do Barreiro está relacionado ao setor "Emprego e

${ }^{10}$ Em relação aos anos de 2001 até 2004, não consta nenhum relatório no site do Sistema FIRJAN. 
Renda". Este segmento, entre os anos 2005 e 2011, obteve média anual de 0,3617 (baixo nível de desenvolvimento). Nesse período, o município obteve variação positiva de $8,98 \%$, devido à recuperação apresentada em $2011(0,3861)$. Nesse segmento, a melhor nota obtida pelo município foi em 2008 (0,4505) e a pior, em 2007 (0,2161). Os anos seguintes, 2009 e 2010, retomaram a sequência de queda com notas 0,4029 e 0,2720 ; respectivamente.

Gráfico 3 - Variação do IFDM em São José do Barreiro entre 2005 e 2011

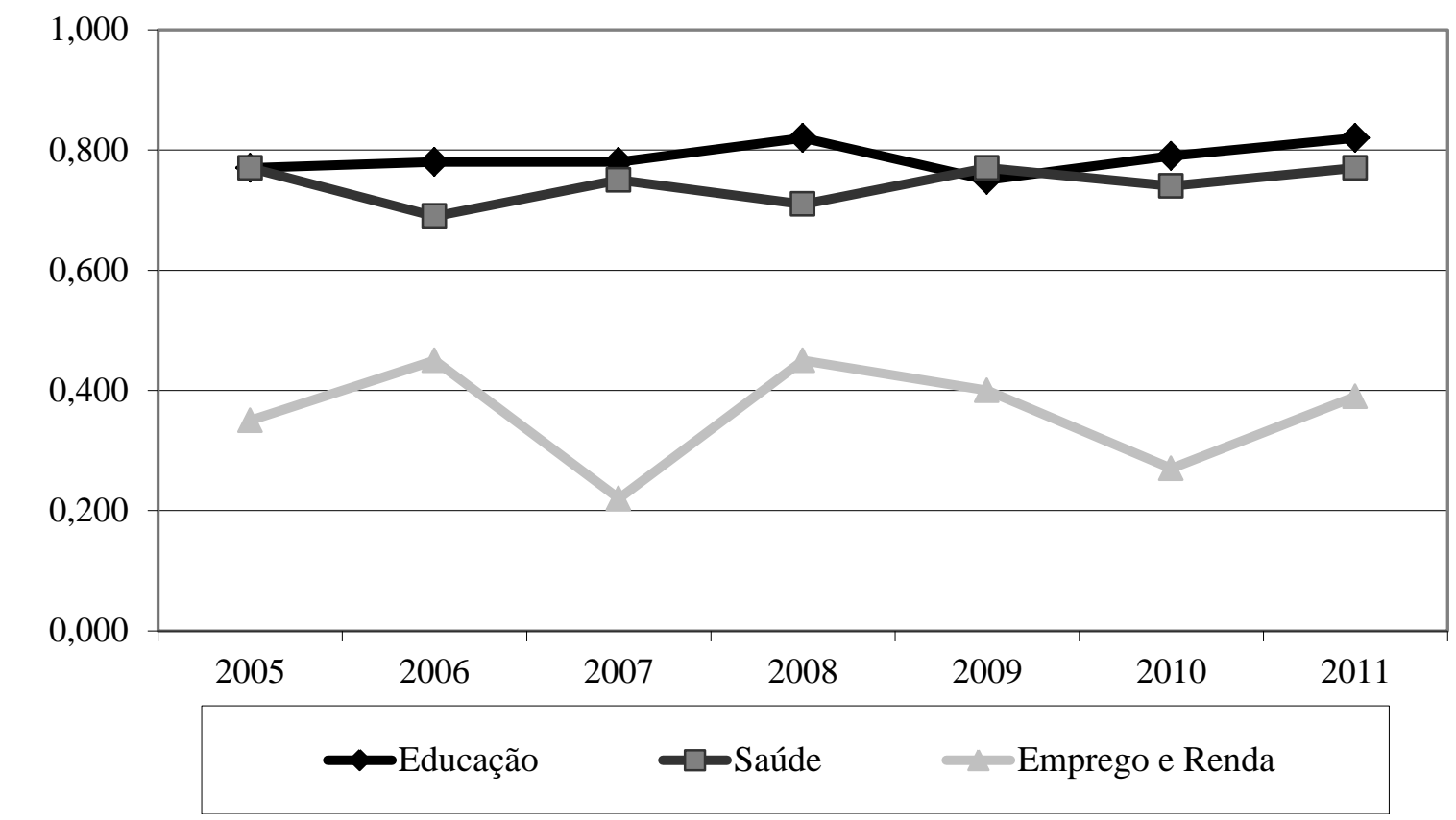

Fonte: IFDM (2014).

$\mathrm{Na}$ área da educação, a cidade conseguiu saltar do nível de desenvolvimento moderado $(0,7727)$ para o patamar de alto grau de desenvolvimento $(0,8231)$. No período de 2005 a 2011, o segmento educacional obteve crescimento de $6,52 \%$.

O setor de saúde foi o único segmento que apresentou variação negativa $(0,10 \%)$ no período. No primeiro ano de análise, em 2005, São José do Barreiro obteve nota 0,7727 e, em 2011 , teve como resultado a nota 0,7709 .

Os resultados indicam que São José do Barreiro encontra dificuldades para se manter no estágio com desenvolvimento moderado. A dificuldade de geração de empregos formais impacta diretamente os indicadores sociais do município.

\subsection{ECONOMIA SOLIDÁRIA COMO ALTERNATIVA AO DESENVOLVIMENTO DO MUNICÍPIO DE SÃO JOSE DO BARREIRO}

Os baixos índices de desenvolvimento no município apontam que a economia solidária pode ser uma alternativa de desenvolvimento. A ausência de interesse dos grandes capitalistas, como por exemplo, do setor industrial amplia a necessidade de busca de novos 
horizontes que possam contribuir com o crescimento da economia e ao mesmo tempo valorizar as características locais. Por exemplo, ações na área de turismo histórico e cultural são alternativas. O município possui significativo patrimônio histórico e cultural resultante da sua trajetória, com destaque para o período de apogeu da cultura cafeeira. Esses recursos podem ser utilizados para favorecer ações consorciadas entre pequenos produtores locais relacionados ao turismo e ao artesanato, com a elevação da competitividade dos agentes econômicos locais. A economia solidária constitui referencia para organização dos trabalhadores locais de modo a instrumentalizar o turismo histórico e o artesanato para o desenvolvimento local.

Depreende-se que a ausência de interesse do capital externo em municípios como São José do Barreiro implica em outros mecanismos para o alcance do desenvolvimento econômico, como os empreendimentos que valorizem o potencial local na articulação de forças, aproveitando programas de políticas públicas nacionais e estaduais. Há necessidade de unir esforços para a realização de parcerias entre entidades públicas e privadas, para as ações em prol do desenvolvimento com empreendimentos que contribuam a geração de emprego e renda associada à valorização da cultura local (VIEIRA, 2009).

A área de agricultura familiar pode contribuir para que sejam elaboradas políticas que promovam a valorização dos produtos e serviços da agricultura cooperada e/ou famíliar, a fim de que incorra em parcerias do setor privado, sociedade civil, além de organizações públicas, o que resulta em vantagens para os agricultores familiares por meio da ampliação para a oportunidade de negócios com acesso aos compradores incluindo-os em uma cadeia de suprimentos qualificada.

Assim, a facilitação do acesso às informações dos serviços públicos de fomento à agricultura, tal como o Programa Nacional de Agricultura Familiar (PRONAF) com vistas à melhorar o atendimento ao produtor rural, promove não somente desenvolvimento de atividades produtivas, mas também, a cidadania. Aprimorar a competitividade por intermédio de condições adequadas à continuidade e crescimento dos produtos agropecuários, nos dias atuais dá se com o apoio ao uso técnicas e insumos, a qual se dará com o aprimoramento das práticas de manejo, mecanização da produção e melhoria do plantel.

Concomitantemente, tais ações fortalecem a identificação dos produtos característicos da Microrregião de Bananal, onde está localizado o município de São José do Barreiro e, ao mesmo tempo difunde sua expansão no mercado, decorrente da capacitação técnica dos agricultores garantindo a qualidade e a manutenção produtiva. No médio prazo, a formação de um Arranjo Produtivo Local agropecuário regional identificará os produtores e demandará a elaboração de programas específicos para suplantar as dificuldades locais. Trata-se da elaboração de ações locais e regionais amparadas em políticas públicas caracterizadas por contemplar as especificidades de municípios com as características de São José do Barreiro.

A economia solidária constitui-se por práticas e conceitos associados à emancipação dos trabalhadores. Sua implantação corresponde a ruptura com o parâmetro econômico clássico e mesmo o neoliberal, que priorizam a subordinação do trabalho ao capital. Busca-se o empoderamento dos trabalhadores quanto ao controle da riqueza produzida, o que pode ocorrer com ações de controle da produção e de acesso aos consumidores. Por exemplo, na produção de artesanato e trabalhos manuais a criatividade consiste na geração de ideias, as quais em determinadas situações colaboram para o enfrentamento de problemas para a 
inserção de produtos e serviços no mercado, por meio da inovação, que é processo pelo qual as ideias são transformadas em bens e serviços. A associação de que a inovação demanda altos investimentos pode ser suplantada pela criatividade para galgar o mercado de trabalho, desvinculando-se da competição predatória e, associando a esta a qualidade e preço justo.

Portanto, promover a valorização, bem como a qualificação do artesanato no município de São Jose do Barreiro, a qual se destaca pela produção do "pássaro de madeira" e "crochê", difunde um referencial para a economia criativa regional às Casas do Artesão nos municípios integrantes da referida região. Aprimorar a qualificação dos produtos difundirá a promoção e a comercialização do artesanato regional, e também da cultura típica com a realização das festas regionais e de sua comida típica com a realização de feiras regionais a de Arte e Cultura. A gestão solidária impactará positivamente na constituição de uma rede de fornecedores de matérias primas utilizadas no artesanato da região, promovendo a sustentabilidade social, ambiental e econômica, com a manutenção à fidelidade das técnicas típicas adotadas nos produtos artesanais.

O município também apresenta grande potencial na área de turismo. O município de São José do Barreiro fora foi uma das mais ricas na época da pujança da economia cafeeira; com a existência de fazendas, palacetes, estradas de ferro e outros aspectos de infraestrutura que demonstravam a superioridade no tocante à riqueza local. Mais especificamente RM Vale, pó patrimônio cultural se dá pela colaboração dos indígenas e seus sítios arqueológicos, aldeamentos e caminhos; o contingente africano decorrente da escravatura; os caminhos da corte e dos tropeiros que auxiliaram a constituir as igrejas e capelas com suas arquiteturas, suas imagens e festas, o que formam um legado.

O desenvolvimento regional passa também pela questão cultural e de valores de uma determinada região em que, com o passar do tempo, vão se consolidando e dando identidade a uma comunidade regional. Nas últimas décadas, a historiografia assistiu a um claro crescimento da rejeição à idéia de que a vida social e cultural seja direta e linearmente determinada pelas dimensões da economia e da vida material (VIEIRA; SANTOS, 2012).

A constituição de redes de cooperação fortalece as condições de superação de fragilidades enfrentadas pela sociedade ao que tange o acesso para a ocupação e geração de renda. A dificuldade de articular os agentes econômicos regionais é um desafio a ser enfrentado para o desenvolvimento sustentável.

As redes possibilitam que o público alvo, dentre estes os jovens, elaborem e implementem estratégias para a inserção de suas atividades econômicas nos mercados locais e, concomitantemente, adquirem visibilidade acerca da sua capacidade de atuação como protagonistas de empreendimentos. Constata-se, portanto, uma situação favorável para a constituição de redes solidárias com iniciativas juvenis, haja vista a sinergia de mobilização e produção a ser potencializada desta população. Neste contexto, a articulação e estruturação dos empreendimentos econômicos solidários em uma rede surgem como uma estratégia transversal dialogada entre a organização setorial dos EES como com a organização de cadeias produtivas, sendo que estas organizam as demandas dos empreendedores direcionando de forma planejada a captação de recursos (MTE, 2012). 
As parcerias com os empreendimentos solidários são uma das alternativas na busca do desenvolvimento econômico: um caminho para o crescimento da oferta de trabalho aos jovens, do rendimento familiar, da atração de recursos para o município.

\section{CONSIDERAÇÕES FINAIS}

O objetivo deste trabalho foi analisar o potencial de constituição de empreendimentos de economia solidária em São José do Barreiro. Verificou-se que a riqueza gerada durante o auge do ciclo do café não foi capaz de colocar os municípios da microrregião de Bananal na rota do crescimento econômico. Ao contrário, essas cidades experimentaram estagnação em um primeiro momento e, posteriormente, declínio. Outros fatores que contribuíram para estagnação econômica foram a implantação da linha férrea, no final do século XIX e, depois, na década de 1950, a construção da rodovia Presidente Dutra.

A inserção da economia solidária tem como objetivo apoiar a parcela marginalizada da sociedade e aqueles que buscam alternativas à geração de renda para o sustento de sua família. No caso de São José do Barreiro, verifica-se que um meio de superar esse entrave está na formação de cooperativas de trabalho, dedicadas à produção de artesanato e à agricultura familiar. Os produtos artesanais são criados a partir de objetos obsoletos ou que foram descartados, reforçando o princípio da sustentabilidade. Com relação à agricultura, formula-se a hipótese para a cooperação entre pequenos agricultores, com foco em produtos orgânicos. A distribuição pode ser feita por meio de uma cesta com diversos produtos ou mesmo com produtos separados, além de parcerias com o poder público local para o fornecimento desses alimentos orgânicos às escolas do município. A ideia é formar uma cadeia produtiva eficiente, da formação do produto até o cliente final. Uma maneira de divulgação desses produtos está na inclusão de feiras no calendário da cidade para exposição de produtos artesanais e agrícolas

Outro ponto para ser explorado é o turismo rural e de aventura. São José do Barreiro conta com o Parque Nacional da Serra da Bocaina, onde se encontram diversas cachoeiras, além de raras espécies da fauna e da flora brasileira. Mas, para que esse segmento possa se fortalecer, é necessário que o município tenha uma secretaria de turismo estruturada para assistir os visitantes e instruir a população local na preservação de manifestações culturais locais.

No Brasil, a economia solidária é incentivada por meio de projetos de extensão, entre universidades e comunidades, além de estudos patrocinados por órgãos governamentais em parceria com a sociedade. A economia solidária é um modelo de consumo, produção e distribuição baseado em valores éticos, centrado no desenvolvimento da sociedade. Esse modelo pode ser implantado com base nas teorias de Keynes, que defendem a intervenção estatal na economia.

Portanto, entende-se que seja viável a constituição de projetos de economia solidária em São José do Barreiro como alternativa para o desenvolvimento local. Pois, de acordo com Índice FIRJAN, o gargalo do desenvolvimento do município está relacionado ao setor de emprego. 
Além dos preceitos democráticos, a economia solidária tem importante papel de inclusão social para inserção daquelas pessoas que foram colocadas à margem do sistema econômico tradicional. Ao longo dos anos, o modelo de economia clássica ou neoclássica acarretou o aumento da informalidade e precarização do trabalho. O trabalhador necessita, de alguma forma, garantir o sustento da sua família, mesmo em condições amplamente desfavoráveis. Por este motivo, se sujeita as regras do capital.

Há pouco interesse em investimento de capital dado o baixo retorno dos recursos aplicados. Cabe então buscar soluções locais ou regionais para resolver o problema da estagnação econômica. Apesar das limitações impostas à economia solidária, conclui-se que sua implantação deve ser considerada de maneira conjunta pelos cinco municípios da microrregião de Bananal, entre eles São Jose do Barreiro. Iniciativas locais isoladas estão mais propensas à formação de um monopólio, contrariando os ideais de inclusão da economia solidária. Considerou-se no presente trabalho apenas as condições de um município. Porém, a trajetória dos municípios da microrregião sugere o compartilhar de problemas comuns. A implantação de políticas públicas pautadas na economia solidária sugere a cooperação entre os municípios da microrregião e não na concorrência. Por isso, é necessária uma articulação entre os empreendimentos solidários para possibilitar uma alternativa de transformação social por meio de políticas públicas, geração de trabalho e renda.

\section{REFERÊNCIAS}

AZAMBUJA, L. R. Os valores da economia solidária. Sociologias. Porto Alegre, n. 21, p. 282-317, jan./jun. 2009.

BARRETOS, R. O.; PAULA, A. P. P. Os dilemas da economia solidária: um estudo acerca da atividade de inserção dos indivíduos na lógica cooperativista. Cadernos EBAPE.BR. Rio de Janeiro, v. 7, n. 2, p. 199-213, jan./jun. 2009.

BERTUCCI, J. O. Desenvolvendo a solidariedade no caminho da transição: um ensaio sobre a teoria do socialismo a partir de Marx. Economia e Sociedade, Campinas, v. 19, n. 1, p. 173200, abr. 2010.

BRAGA, A. M. S. et al.. Desenvolvimento: um conceito multidimensional. Desenvolvimento Regional em debate, Canoinhas, n. 1, p. 44-61, jul. 2012.

CARVALHO, F. J. C. Keynes e o Brasil. Economia e Sociedade, Campinas, v. 17, p. 569574, dez. 2008.

ENGELS, F.; KARL, M. Manifesto do partido comunista. 5. ed. Petrópolis: Vozes, 1993. $151 \mathrm{p}$.

FRANCO, M. C. DRS: ampliação de crédito com inclusão social. IN: MELLO, C.; ROVAI, R.; STREIT, J. (orgs). Geração de trabalho e renda, economia solidária e desenvolvimento local: a contribuição da Fundação Banco do Brasil. São Paulo: Publisher Brasil, 2006. 
FREITAS, H.; MOSCAROLA, J. Da observação à decisão: métodos da pesquisa e de análise quantitativa e qualitativa de dados. RAE electron. São Paulo, v. 1, n. 1, p. 1-30, jan./jun. 2002.

GAIGER, L. I. G. A associação econômica dos pobres como via de combate às desigualdades. Caderno CRH. Salvador, v. 22, n. 57, p. 563-580, set./dez. 2009.

GALVÃO, A. C. F. Política de desenvolvimento regional e inovação: lições da experiência europeia. Rio de Janeiro: Garamond, 2004. 272 p.

GODOY, A. S. Pesquisa qualitativa: tipos fundamentais. Administração de Empresas. São Paulo, v. 35, n. 3, p. 20-29, mai./jun. 1995.

GUGLIANO, A. A.; LOCKS, P. Democracia e economia solidária: limitações e potencialidades. Brasileira de Ciência Política. Brasília, n. 10, p. 41-62, jan./abr. 2013.

HARVEY, D. A produção capitalista do espaço. São Paulo: Annablume, 2005.

HUNT, E. K. História do pensamento econômico. Rio de Janeiro: Campus, 1981.

IBGECIDADES. Instituto Brasileiro de Geografia e Estatística. Disponível em: <http://www.ibge.gov.br/cidadesat/topwindow.htm?1>. Acesso em: agosto 2014.

LANZA, L. M. B.; STÁBILE, F. Trajetória do trabalho feminino e economia solidária. IN: CORDEIRO, S. M. S.; LANZA, L. M. B.; PITAGUARI, S. O. (orgs). A sustentabilidade da economia solidária. Londrina: Universidade Estadual de Londrina, 2012.

LAVILLE, J. L. Economia solidária, a perspectiva europeia. Sociedade e Estado. Brasília, v. 16, n. 1-2, p. 57-99, jun./dez. 2001.

LEITE, M. P. A economia solidária e o trabalho associativo: teorias e realidades. Revista Brasileira de Ciências Sociais, São Paulo, v. 24, n. 69, p. 31-51, fev. 2008.

MIRANDA, E. E. de; COUTINHO, A. C. (Coord.). Brasil Visto do Espaço.

Campinas:Embrapa Monitoramento por Satélite, 2004. Disponível em:

http://www.cdbrasil.cnpm.embrapa.br/txt/direitos.php. acessado em: 3 de julho de 2015.

MARX, K. O capital. Tradução de DEVILLE, G. Bauru: Edipro, 1998.

PNUD. Programa das Nações Unidas para o Desenvolvimento. Disponível em: <http://www.pnud.org.br/>. Acesso em: agosto 2014.

RETAMIRO, W. Empreendimentos econômicos solidários no processo de desenvolvimento regional. 2013. 117 f. Dissertação (Mestrado em Planejamento e desenvolvimento Regional) Departamento de Economia, Contabilidade e Administração, Universidade de Taubaté, Taubaté, 2013.

RICCI, F. Indústrias têxteis na periferia origens e desenvolvimento: o caso do Vale do Paraíba. Taubaté: Cabral, 2006.

SANDRONI, P. Novo dicionário de Economia. São Paulo: Best Seller, 1994. 
SEADE. Fundação Sistema Estadual de Análise de Dados. Disponível em: <http://www.seade.gov.br/>. Acesso em: agosto, 2014.

SENAES - Secretaria Nacional de Economia Solidária. O que é Economia Solidária. Brasília: Disponível em: http://portal.mte.gov.br/ecosolidaria/o-que-e-economiasolidaria.htm. Acesso em: 30 jul 2015.

SINGER, P. Economia solidária: um modo de produção e distribuição. IN: SINGER, P.; SOUZA, A. R. (orgs). A economia solidária no Brasil: a autogestão como resposta ao desemprego. 2 ed. São Paulo: Contexto, 2003.

SMITH, A.; BARAÚNA, L. J. A riqueza das nações: investigação sobre sua natureza e suas causas. 2. ed. São Paulo: Nova Cultural, 1985. 2 v. (Os economistas).

VIEIRA, E. T. Industrialização e políticas de desenvolvimento regional: o Vale do Paraíba paulista na segunda metade do século XX. 2009. 177 f. Tese (Doutorado em História Econômica) Faculdade de Filosofia, Letras e Ciências Humanas, Universidade de São Paulo, São Paulo, 2009.

VIEIRA, E. T.; SANTOS, M. J. Desenvolvimento econômico regional - uma revisão histórica e teórica. G\&DR, Taubaté, v. 8, n. 2, p. 344-369, mai/ago. 2012.

Artigo recebido em: 28/04/2015

Artigo aprovado em: 30/08/2015 